http://dx.doi.org/10.15407/dopovidi2016.10.035

УДК 534.3

\title{
А.О. Борисюк
}

Інститут гідромеханіки НАН України, Київ

E-mail: aobor@ukr.net

\section{Функція Гріна тривимірного конвективного рівняння Гельмгольца для нескінченної прямої труби}

(Представлено академіком НАН України В.Т. Грінченком)

Побудовано функцію Гріна тривимірного конвективного рівняння Гельмгольца для нескінченної прямої труби довільної (але незмінної по ї довжині) форми та площі поперечного перерізу з акустично жорсткими і акустично м'якими стінками, а також зі стінками змішаного типу. Ця функція представляється рядом за акустичними модами зазначеної конструкції. В ній у явному вигляді відображені ефекти рівномірної осередненої течї в трубі. Ці ефекти стають вагомішими зі збільшенням числа Маха течї, зумовлюючи, зокрема, появу і подальше збільшення асиметрї функції відносно поперечного перерізу труби, в якому розташоване акустичне джерело. I навпаки, зі зменшенням числа Маха вагомість впливу течї на функцію Гріна зменшується, проявляючись, окрім іншого, у зменшенні зазначеної ї асиметрії. У випадку ж відсутності течї̈ одержана функція Гріна є симетричною відносно вказаного перерізу.

Ключові слова: функція Гріна, конвективне рівняння Гельмгольца, пряма труба.

Задачі знаходження й дослідження згенерованих у трубах акустичних полів є актуальними для автомобіле- та літакобудування, нафтогазової промисловості, медицини, архітектури, комунального господарства тощо [1-4]. Всі вони, незалежно від типу й геометрії труб, а також типу акустичних джерел у них, у принципі можуть бути розв’язані методом функцій Гріна. Однак застосування цього методу доцільне лише за умови існування принципової можливості побудови відповідної функції Гріна.

Така можливість, окрім кваліфікації дослідника, залежить від багатьох факторів. Серед них - геометрія досліджуваної труби та форма iï поперечного перерізу, фізичні властивості їі стінок та умови її закріплення, фізичні властивості зовнішнього та внутрішнього середовищ, акустичні умови на кінцях труби, наявність або відсутність течії в ній тощо. Як засвідчує аналіз наукової літератури, з-поміж циліндричних конструкцій, геометрія та фізичні властивості яких визначаються різними комбінаціями цих факторів, донедавна найбільш дослідженими були нескінченні прямі жорсткостінні труби кругової та прямокутної форм поперечного перерізу (див., наприклад, [1, 5-10]). Для них були побудовані відповідні функції Гріна хвильового рівняння й рівняння Гельмгольца, а також з їхньою допомогою одержані вирази для різних характеристик акустичних полів, згенерованих відповідними джерелами у зазначених трубах. Проте всі ці результати зазвичай обмежувалися випадком відсутності течії в трубі. Якщо ж наявність течії і

(C) А.О. Борисюк, 2016 


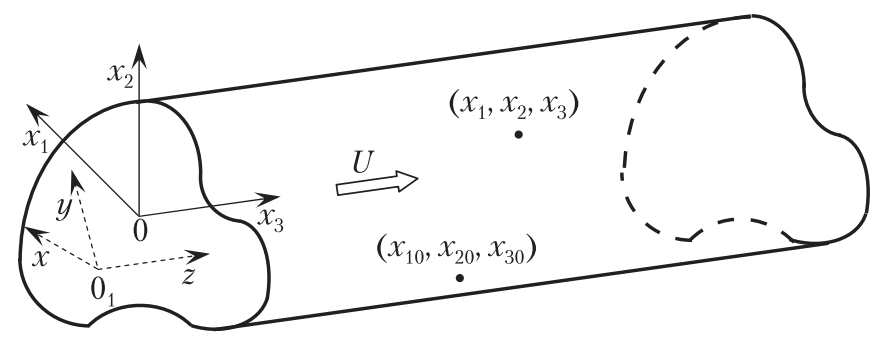

Puc. 1. Геометрія задачі

бралася до уваги, то її ефекти у відповідних функціях Гріна та/або кінцевих результатах проявлялися лише у неявному вигляді [1, 5, 6, 8-10].

Цей недолік був частково виправлений у недавніх роботах [11-14]. Там були побудовані функції Гріна тривимірного хвильового рівняння для прямих труб різних форм поперечного перерізу (включаючи й довільну) з різноманітним типом стінок і внутрішньою рівномірною осередненою течією [11-14], а також функції Гріна тривимірного рівняння Гельмгольца для прямої жорсткостінної труби кругового та прямокутного поперечного перерізу з такою ж течією [11, 14]. У цих функціях, окрім іншого, вже у явному вигляді були відображені ефекти зазначеної течії.

У даному дослідженні розвиваються й узагальнюються результати робіт [11-14] для тривимірного конвективного рівняння Гельмгольца для нескінченної прямої труби довільної (але незмінної по ії довжині) форми та площі поперечного перерізу з акустично жорсткими, або акустично м'якими стінками, або ж зі стінками змішаного типу. Одержані при цьому результати мають явну залежність від параметрів течії в трубі.

Постановка задачі. На рис. 1 зображено нерухому нескінченну пряму трубу довільної (але незмінної по їі довжині) форми та площі поперечного перерізу. Її стінки є акустично жорсткими або акустично м’якими, або ж якась їхня частина є акустично жорсткою, а решта - акустично м'якою ${ }^{1}$. У цій трубі задано рівномірну осереднену по їі поперечному перерізу течію рідини зі швидкістю $U$ у напрямку твірної їі стінки ${ }^{2}$, а також як завгодно розташовані нерухомі акустичні джерела різної природи. Останні генерують у трубі акустичне поле. Довільна частотна компонента цього поля описується тривимірним конвективним рівнянням Гельмгольца [11]:

$$
\nabla^{2} \breve{p}_{a}+k_{0}^{2} \breve{p}_{a}+\mathrm{i} 2 k_{0} \mathrm{M} \frac{\partial \breve{p}_{a}}{\partial x_{3}}-\mathrm{M}^{2} \frac{\partial^{2} \breve{p}_{a}}{\partial x_{3}^{2}}=\breve{\gamma}, \quad\left(x_{1}, x_{2}\right) \in A, \quad\left|x_{3}\right|<\infty .
$$

Необхідно побудувати функцію Гріна рівняння (1) для цієї труби.

У рівнянні (1) $\breve{p}_{a}$ є частотним образом Фур'є акустичного тиску $p_{a} ; k_{0}=\omega / c_{0}-$ акустичним хвильовим числом; $i=\sqrt{-1}-$ комплексною одиницею; $\mathrm{M}=U / c_{0}-$ числом Маха течії в трубі; $\breve{\gamma}-$ частотним образом Фур'є функції $\gamma$, котра описує сумарний розподіл зазначених акустичних джерел; $\omega$ - коловою частотою; $c_{0}-$ швидкістю звуку в незбуреній рідині; $x_{1}, x_{2}, x_{3}-$ вибраними на рис. 1 ортогональними, у загальному випадку криволінійними координатами з віссю $x_{3}$ уздовж течії; $A-$ поперечним перерізом труби площею $|\mathrm{A}| ; \nabla^{2}$-оператором Лапласа, який у системі координат $\left(x_{1}, x_{2}, x_{3}\right)$ записується таким чином:

$$
\nabla^{2}=\frac{1}{\mathrm{~h}_{1} \mathrm{~h}_{2}}\left[\frac{\partial}{\partial x_{1}}\left(\frac{\mathrm{h}_{2}}{\mathrm{~h}_{1}} \frac{\partial}{\partial x_{1}}\right)+\frac{\partial}{\partial x_{2}}\left(\frac{\mathrm{h}_{1}}{\mathrm{~h}_{2}} \frac{\partial}{\partial x_{2}}\right)+\mathrm{h}_{1} \mathrm{~h}_{2} \frac{\partial^{2}}{\partial x_{3}^{2}}\right]
$$

1 Тут мається на увазі така форма поперечного перерізу труби і такий тип іï стінок, для яких можна знайти іï акустичні моди.

2 У даній роботі розглядаються такі швидкості руху рідини, при яких коливання стінок труби (в разі їх існування) будуть малими (щоб зберегти лінійність задачі). 
$\mathrm{h}_{i}(i=1,2,3)-$ коефіцієнтами Ляме [14]:

$$
\begin{aligned}
& \mathrm{h}_{i}=\sqrt{\left(\frac{\partial x}{\partial x_{i}}\right)^{2}+\left(\frac{\partial y}{\partial x_{i}}\right)^{2}+\left(\frac{\partial z}{\partial x_{i}}\right)^{2}}, \\
& \mathrm{~h}_{1}=\mathrm{h}_{1}\left(x_{1}, x_{2}\right), \mathrm{h}_{2}=\mathrm{h}_{2}\left(x_{1}, x_{2}\right), \mathrm{h}_{3}=1 ;
\end{aligned}
$$

a $x, y, z$ - прямокутними декартовими координатами, вибраними таким чином, що [14] їх початок лежить у тому ж поперечному перерізі труби, що і початок системи координат $\left(x_{1}, x_{2}, x_{3}\right)$, вісь $z$ співспрямована з віссю $x_{3}$.

Крім того, згідно з умовою задачі,

$$
\frac{\partial U}{\partial t}=0, \frac{\partial U}{\partial x_{1}}=0, \frac{\partial U}{\partial x_{2}}=0, \frac{\partial U}{\partial x_{3}}=0, \frac{\partial A}{\partial x_{3}}=0,|A|=\text { const } .
$$

Функція Гріна. Рівняння та умови, які задовольняє функція Гріна. Шукана функція Гріна G задовольняє таке рівняння:

$$
\begin{aligned}
& \nabla^{2} \tilde{\mathrm{G}}+k_{0}^{2} \tilde{\mathrm{G}}+i 2 k_{0} \mathrm{M} \frac{\partial \tilde{\mathrm{G}}}{\partial x_{3}}-\mathrm{M}^{2} \frac{\partial^{2} \tilde{\mathrm{G}}}{\partial x_{3}^{2}}=-\frac{1}{2 \pi} \delta\left(\vec{r}-\vec{r}_{0}\right), \\
& \left(x_{1}, x_{2}\right) \in A,\left(x_{10}, x_{20}\right) \in A,\left|x_{3}\right|<\infty,\left|x_{30}\right|<\infty,
\end{aligned}
$$

в якому

$$
\delta\left(\vec{r}-\vec{r}_{0}\right)=\frac{1}{h_{1} h_{2}} \delta\left(x_{1}-x_{10}\right) \delta\left(x_{2}-x_{20}\right) \delta\left(x_{3}-x_{30}\right)
$$

є тривимірною просторовою, а $\delta\left(x_{i}-x_{i 0}\right)(i=1,2,3)-$ одновимірними просторовими дельтафункціями Дірака, $\vec{r}=x_{i} \vec{e}_{i}$ і $\vec{r}_{0}=x_{i 0} \vec{e}_{i}$ - радіус-векторами відповідно точки поля і вищезазначеного джерела; $\vec{e}_{i}$ - ортами координатних осей $x_{i}$, а оператор $\nabla^{2}$ дається виразом (2) (тут передбачається підсумовування по індексах, що повторюються). Вона описує акустичний тиск у довільній точці труби $\left(x_{1}, x_{2}, x_{3}\right)$, який генерується на частоті $\omega$ точковим акустичним джерелом, розташованим у трубі в точці $\left(x_{10}, x_{20}, x_{30}\right)$ (див. рис. 1$)$.

Граничними умовами для функції $\tilde{\mathrm{G}} €$ рівність нулю нормальної компоненти акустичної швидкості на стінці труби $S$ (у разі її акустичної жорсткості):

$$
\left.\frac{\partial \tilde{\mathrm{G}}}{\partial n}\right|_{S}=0
$$

або відсутність акустичного тиску на $S$ (у разі акустичної м’якості стінки):

$$
\left.\tilde{\mathrm{G}}\right|_{S}=0
$$

або ж, у разі акустичної жорсткості певної частини стінки $S$ (наприклад, $S_{1}$ ) і акустичної м'якості решти стінки труби $\left(S_{2}=S-S_{1}\right)$, відсутність зазначених характеристик акустичного поля на відповідних частинах поверхні $S$ :

$$
\left.\frac{\partial \tilde{\mathrm{G}}}{\partial n}\right|_{S_{1}}=0,\left.\tilde{\mathrm{G}}\right|_{S_{2}}=0, S_{1}+S_{2}=S
$$

(тут $\vec{n}-$ зовнішня нормаль до стінки $S$, а поверхні $S_{1}$ та $S_{2}$ можуть складатися з кількох областей).

Крім цього, не повинно бути відбиття звуку на кінцях труби (на нескінченності), а також має виконуватися принцип взаємності [7-10, 14]:

$$
\tilde{\mathrm{G}}\left(\vec{r}, \vec{r}_{0} ; \omega\right)=\tilde{\mathrm{G}}\left(\vec{r}_{0}, \vec{r} ; \omega\right) .
$$


Побудова функції Гріна та їі аналіз. Перш ніж переходити до розв’язування сформульованої у попередньому підрозділі задачі (4)-(8), звернемо увагу на те, що вона є частотним образом Фур’є задачі для функції Гріна G відповідного конвективного хвильового рівняння, яку розв’язано у роботі [14]. А відтак, в принципі, шукану функцію Гріна $\tilde{G}$ можна формально одержати з функції $\mathrm{G}$ шляхом застосування до останньої відповідного прямого часового перетворення Фур’є. Однак такий формалізм може призвести до того, що якісь важливі фізичні особливості процесу генерації та поширення звуку в досліджуваній трубі залишаться поза увагою. А тому доцільнішим видається безпосереднє розв’язування задачі (4)-(8).

Виходячи зі сказаного, розв'язок зазначеної граничної задачі шукатимемо у вигляді ряду за акустичними модами труби $\Psi_{n m}$ :

$$
\tilde{\mathrm{G}}\left(x_{1}, x_{2}, x_{3}, x_{10}, x_{20}, x_{30} ; \omega\right)=\sum_{n} \sum_{m} \tilde{\mathrm{G}}_{n m}\left(x_{3}, x_{10}, x_{20}, x_{30} ; \omega\right) \Psi_{n m}\left(x_{1}, x_{2}\right) .
$$

Таке представлення функції $\tilde{\mathrm{G}}$ задовольняє (залежно від типу стінок труби) одну із граничних умов (5)-(7), а його невідомі коефіцієнти $\tilde{\mathrm{G}}_{n m}-$ одновимірне конвективне рівняння Гельмгольца

$$
\begin{aligned}
& \left(1-\mathrm{M}^{2}\right) \frac{\partial^{2} \tilde{\mathrm{G}}_{n m}}{\partial x_{3}^{2}}+k_{f n m}^{2} \tilde{\mathrm{G}}_{n m}+i 2 k_{0} \mathrm{M} \frac{\partial \tilde{\mathrm{G}}_{n m}}{\partial x_{3}}=-\frac{1}{2 \pi} \frac{\Psi_{n m}\left(x_{10}, x_{20}\right)}{\left\|\Psi_{n m}\right\|^{2}} \delta\left(x_{3}-x_{30}\right), \\
& k_{f n m}=\sqrt{k_{0}^{2}-k_{n m}^{2}}, \quad\left(x_{10}, x_{20}\right) \in A,\left|x_{3}\right|<\infty,\left|x_{30}\right|<\infty .
\end{aligned}
$$

Його одержуємо з рівняння (4) після підстановки туди ряду (9), подальшого множення отриманого при цьому співвідношення скалярно на моди $\Psi_{n m}$, а також урахування ортогональності останніх:

$$
\begin{aligned}
& \iint_{A} \Psi_{n m}\left(x_{1}, x_{2}\right) \Psi_{s q}\left(x_{1}, x_{2}\right) d \mathrm{~A}= \begin{cases}\left\|\Psi_{n m}\right\|^{2},(s, q)=(n, m), \\
0, & (s, q) \neq(n, m),\end{cases} \\
& \left\|\Psi_{n m}\right\|^{2}=\iint_{A} \Psi_{n m}^{2}\left(x_{1}, x_{2}\right) d \mathrm{~A}, \mathrm{~d} A=\mathrm{h}_{1} \mathrm{~h}_{2} \mathrm{~d} x_{1} \mathrm{dx}_{2}
\end{aligned}
$$

і рівняння

$$
\nabla_{\left(x_{1}, x_{2}\right)}^{2} \Psi_{n m}\left(x_{1}, x_{2}\right)=-k_{n m}^{2} \Psi_{n m}\left(x_{1}, x_{2}\right),
$$

яке функції $\Psi_{n m}$ мають задовольняти.

У співвідношеннях (9)-(12)

$$
\nabla_{\left(x_{1}, x_{2}\right)}^{2}=\frac{1}{\mathrm{~h}_{1} \mathrm{~h}_{2}}\left[\frac{\partial}{\partial x_{1}}\left(\frac{\mathrm{h}_{2}}{\mathrm{~h}_{1}} \frac{\partial}{\partial x_{1}}\right)+\frac{\partial}{\partial x_{2}}\left(\frac{\mathrm{h}_{1}}{\mathrm{~h}_{2}} \frac{\partial}{\partial x_{2}}\right)\right]
$$

$€$ оператором Лапласа у координатах $x_{1}, x_{2}, k_{n m}$ - модальними хвильовими числами у поперечному перерізі труби; $k_{f n m}-$ модальними осьовими хвильовими числами, а $\left\|\Psi_{n m}\right\|^{2}-$ квадратами норм мод $\Psi_{n m}$. Кількість же мод $\Psi_{n m}$ та межі сум у представленні (9) залежать від форми поперечного перерізу труби і типу їі стінок.

Розв’язок одновимірного конвективного рівняння Гельмгольца (10) можна одержати з розв'язку його класичного одновимірного аналогу, до якого можна звести (10) шляхом виконання математичних операцій, використаних у роботі [11]. Для цього перепишемо невідомі функції $\tilde{\mathrm{G}}_{n m}$ У такому вигляді:

$$
\tilde{\mathrm{G}}_{n m}\left(x_{3}, x_{10}, x_{20}, x_{30} ; \omega\right)=\frac{\lambda l}{c_{0}} \mathrm{e}^{-\mathrm{i} \lambda^{2} \mathrm{M} k_{0}\left(x_{3}-x_{30}\right)} \hat{\mathrm{G}}_{n m}\left(X_{3}, x_{10}, x_{20}, X_{30} ; \Omega\right),
$$


після чого підставимо представлення (13) у рівняння (10). Це приводить до рівняння для введених у (13) функцій $\hat{\mathrm{G}}_{n m}$ :

$$
\frac{\partial^{2} \hat{\mathrm{G}}_{n m}}{\partial X_{3}^{2}}+K_{f n m}^{2} \hat{\mathrm{G}}_{n m}=-\frac{1}{2 \pi} \frac{c_{0} l}{\lambda} \frac{\Psi_{n m}\left(x_{10}, x_{20}\right)}{\left\|\Psi_{n m}\right\|^{2}} \delta\left(\frac{l}{\lambda}\left(X_{3}-X_{30}\right)\right)
$$

в області

$$
\left|X_{3}\right|<\infty,\left|X_{30}\right|<\infty .
$$

Рівняння (14) є класичним одновимірним рівнянням Гельмгольца, в якому $X_{3}=\lambda x_{3} / l$, $X_{30}=\lambda x_{30} / l-$ безрозмірні осьові координати; $\Omega=\lambda \omega l / c_{0}=\lambda k_{0} l-$ безрозмірна частота, $\lambda=1 / \sqrt{1-M^{2}}-$ безрозмірний параметр; $l$ - масштаб довжини, який можна вибирати довільним чином [14], а $K_{f n m}=\sqrt{\Omega^{2}-k_{n m}^{2} l^{2}}=\sqrt{\lambda^{2} k_{0}^{2}-k_{n m}^{2}} l-$ безрозмірні модальні осьові хвильові числа.

3 урахуванням умови випромінювання у нескінченність, яку має задовольняти функція $\tilde{\mathrm{G}}$ (а тому внаслідок співвідношень (9) і (13), і коефіцієнти $\hat{\mathrm{G}}_{n m}$ ), розв’язок рівняння (14) для нескінченної області набуває такого вигляду [11]:

$$
\hat{\mathrm{G}}_{n m}=\frac{i c_{0}}{4 \pi K_{f n m}} \frac{\Psi_{n m}\left(x_{10}, x_{20}\right)}{\left\|\Psi_{n m}\right\|^{2}} e^{i K_{f n m}\left|X_{3}-X_{30}\right|} .
$$

Тоді з представлення (13) і виразу (15) одержуємо розв’язок рівняння (10):

$$
\tilde{\mathrm{G}}_{n m}=\frac{i \lambda}{4 \pi \sqrt{\lambda^{2} k_{0}^{2}-k_{n m}^{2}}} \frac{\Psi_{n m}\left(x_{10}, x_{20}\right)}{\left\|\Psi_{n m}\right\|^{2}} e^{i\left(\lambda \sqrt{\lambda^{2} k_{0}^{2}-k_{n m}^{2}}\left|x_{3}-x_{30}\right|-\lambda^{2} \mathrm{M} k_{0}\left(x_{3}-x_{30}\right)\right)} .
$$

Підстановка ж співвідношення (16) у ряд (9) дає остаточний вираз для шуканої функції Гріна $\tilde{G}$ тривимірного конвективного рівняння Гельмгольца (1):

$$
\tilde{\mathrm{G}}=\frac{\mathrm{i} \lambda}{4 \pi} e^{-\mathrm{i} \lambda^{2} M k_{0}\left(x_{3}-x_{30}\right)} \sum_{n} \sum_{m} \frac{\Psi_{n m}\left(x_{10}, x_{20}\right)}{\left\|\Psi_{n m}\right\|^{2}} \Psi_{n m}\left(x_{1}, x_{2}\right) \frac{e^{\mathrm{i} \lambda \sqrt{\lambda^{2} k_{0}^{2}-k_{n m}^{2}}\left|x_{3}-x_{30}\right|}}{\sqrt{\lambda^{2} k_{0}^{2}-k_{n m}^{2}}}
$$

(межі зміни координат точки поля $\left(x_{1}, x_{2}, x_{3}\right)$ й акустичного джерела $\left(x_{10}, x_{20}, x_{30}\right)$ у функції $\tilde{\mathrm{G}}$ наведені після рівняння (4)).

Аналіз співвідношення (17) показує, що побудована функція Гріна $\tilde{G}$ записується у вигляді ряду за акустичними модами труби $\Psi_{n m}$. Вона також задовольняє принцип взаємності (8), умову випромінювання у нескінченність, а також залежно від розглянутих вище типів стінок труби, одну з граничних умов (5)-(7). Крім цього, в (17) через числа М і $\lambda$ в явному вигляді відображено вплив рівномірної осередненої течії в трубі на функцію G. Цей вплив зростає зі збільшенням числа Маха M, спричинюючи, окрім іншого, появу і подальше збільшення асиметрії функції $\tilde{\mathrm{G}}$ відносно поперечного перерізу труби $x_{3}=x_{30}$, в якому розташоване точкове акустичне джерело (див. рис. 1). Натомість зменшення числа М зумовлює послаблення впливу течії на функцію $\tilde{\mathrm{G}}$, зокрема, зменшення зазначеної іiї асиметрії. У випадку ж відсутності течії $(\mathrm{M}=0, \lambda=1)$ функція (17) є симетричною відносно перерізу $x_{3}=x_{30}$ :

$$
\left.\tilde{\mathrm{G}}\right|_{\mathrm{M}=0}=\frac{\mathrm{i}}{4 \pi} \sum_{n} \sum_{m} \frac{\Psi_{n m}\left(x_{10}, x_{20}\right)}{\left\|\Psi_{n m}\right\|^{2}} \Psi_{n m}\left(x_{1}, x_{2}\right) \frac{\mathrm{e}^{\mathrm{i} \sqrt{k_{0}^{2}-k_{n m}^{2}}\left|x_{3}-x_{30}\right|}}{\sqrt{k_{0}^{2}-k_{n m}^{2}}} .
$$

Таким чином, розробленим у даній роботі методом побудовано функцію Гріна $\tilde{G}$ тривимірного конвективного рівняння Гельмгольца для нескінченної прямої труби довільної (але незмінної по її довжині) форми та площі поперечного перерізу з акустично жорсткими й акустично 
м’якими стінками, а також зі стінками змішаного типу ${ }^{1}$. Вона представляється рядом за акустичними модами труби.

У побудованій функції Гріна в явному вигляді відображені ефекти рівномірної осередненої течії в трубі. Ці ефекти стають вагомішими зі збільшенням числа Маха течії, зумовлюючи, зокрема, появу і подальше збільшення асиметрії функції $\tilde{\mathrm{G}}$ відносно поперечного перерізу труби $x_{3}=x_{30}$, в якому розташоване акустичне джерело. I навпаки: зі зменшенням числа Маха вагомість впливу течії на функцію $\tilde{\mathrm{G}}$ зменшується, проявляючись, окрім іншого, у зменшенні зазначеної їі асиметрії. У випадку ж відсутності течії функція $\tilde{\mathrm{G}}$ є симетричною щодо переpiзу $x_{3}=x_{30}$.

У разі виконання умов, зазначених у примітці 1, а також за умови збереження лінійності задачі ${ }^{2}$ цей метод може бути розширений на випадок прямих труб довільної форми поперечного перерізу з довільним типом стінок.

Запропонований у даній роботі підхід створює основи для подальшого розроблення аналітичних методів кількісного знаходження характеристик акустичних полів, які генеруються у трубах з нерегулярною геометрією та внутрішньою течією.

\section{ЦИТОВАНА ЛІТЕРАТУРА}

1. Борисюк А.О. Генерація звуку обмеженою областю збуреної течії в жорсткостінному каналі кругового поперечного перерізу. Ч. 1. Загальна теорія // Акуст. вісн. - 2003. - 6, № 3. - С. 3-9.

2. Berger S.A., Jou L.-D. Flows in stenotic vessels // Ann. Rev. Fluid Mech. - 2000 - 32. - P. 347-382.

3. Вовк И.В., Гринченко В. Т., Малюга В. С. Особенности движения среды в каналах со стенозами // Прикл. гідромеханіка. -2009 . - 11, № 4. - С. 17-30.

4. Young D.F. Fluid mechanics of arterial stenosis // J. Biomech. Eng. - 1979. - 101. - P. 157-175.

5. Davies H.G., Ffowcs Williams J.E. Aerodynamic sound generation in a pipe // J. Fluid Mech. - 1968. - 32, № 4. P. 765-778.

6. Doak P.E. Excitation, transmission and radiation of sound from source distributions in hard-walled ducts of finite length (1): the effects of duct cross-section geometry and source distribution space-time pattern // J. Sound Vib. 1973. - 31, № 1. - P. 1-72.

7. Morse P.M., Ingard K.U. Theoretical acoustics. - New York: McGraw-Hill, 1968. - 927 p.

8. Howe M.S. Acoustics of fluid-structure interactions. - Cambridge: Cambridge Univ. Press, 1998. - 560 p.

9. Грінченко В.T., Вовк I.В., Маципура В.Т. Основи акустики. - Київ: Наук. думка, 2007. - 640 с.

10. Голдстейн M.E. Аэроакустика. - Москва: Машиностроение, 1981. - 294 с.

11. Борисюк А.О. Функції Гріна хвильового рівняння й рівняння Гельмгольца для нескінченного прямого жорсткостінного каналу кругового поперечного перерізу з осередненою течією // Акуст. вісн. - 2011. - 14, № 4. C. $9-17$.

12. Borisyuk A.O. Green's function of the convective wave equation for a rigid rectangular pipe // Наукоємні технології. - 2014. - № 3 (23). - С. 374-378.

13. Борисюк А.О. Функція Гріна конвективного хвильового рівняння для нескінченної прямої жорсткостінної труби прямокутного поперечного перерізу // Доп. НАН України. - 2015. - № 3. - С. 40-44.

14. Борисюк А.О. Функція Гріна тривимірного конвективного хвильового рівняння для нескінченної прямої труби // Доп. НАН України. - 2015. - № 12. - С. 33-40.

\section{REFERENCES}

1. Borysyuk A.O. Acoustic Bulletin, 2003, 6, No 3: 3-9 (in Ukrainian).

2. Berger S.A., Jou L.-D. Ann. Rev. Fluid Mech., 2000, 32: 347-382.

3. Vovk I.V., Grinchenko V.T., Malyuga V. S. Appl. Hydromech., 2009, 11, No. 4: 17-30 (in Russian).

4. Young D.F. J. Biomech. Eng., 1979, 101: 157-175.

5. Davies H.G., Ffowcs Williams J.E. J. Fluid Mech., 1968, 32, No 4: 765-778.

6. Doak P.E. J. Sound Vib., 1973, 31, No 1: P. 1-72.

7. Morse P.M., Ingard K.U. Theoretical acoustics, New York: McGraw-Hill, 1968.

8. Howe M.S. Acoustics of fluid-structure interactions. Cambridge: Cambridge Univ. Press, 1998.

9. Grinchenko V.T., Vovk I.V., Matcypura V.T. Fundamentals of Acoustics. Kiev: Nauk. Dumka, 2007 (in Ukrainian).

10. Goldstein M.E. Aeroacoustics. Moscow: Mashynostroenie, 1981 (in Russian).

11. Borysyuk A.O. Acoustic Bulletin, 2011, 14, No 4: 9-17 (in Ukrainian). 
12. Borysyuk A.O. Science-Based Technologies, 2014, No 3 (23): 374-378.

13. Borysyuk A.O. Dopov. Nac. akad. nauk Ukr., 2015, No 3: 40-44 (in Ukrainian).

14. Borysyuk A.O. Dopov. Nac. akad. nauk Ukr., 2015, No 12: 33-40 (in Ukrainian).

Надійшло до редакиї 02.032016

\section{А.А. Борисюк}

Институт гидромеханики НАН Украины, Киев

E-mail: aobor@ukr.net

\section{ФУНКЦИЯ ГРИНА ТРЕХМЕРНОГО КОНВЕКТИВНОГО УРАВНЕНИЯ ГЕЛЬМГОЛЬЦА ДЛЯ БЕСКОНЕЧНОЙ ПРЯМОЙ ТРУБЫ}

Построена функиия Грина трехмерного конвективного уравнения Гельмгольиа для бесконечной прямой трубы произвольной (но неизменной по ее длине) формы и площади поперечного сечения с акустически жесткими и акустически мягкими стенками, а также со стенками смешанного типа. Эта функиия представляется рядом по акустическим модам указанной конструкции. В ней в явном виде отражены эффекты равномерного осредненного течения в трубе. Эти эффекты становятся более существенными с увеличением числа Маха течения, приводя, в частности, к появлению и дальнейшему увеличению асимметрии функиии относительно поперечного сечения трубы, в котором находится акустический источник. И наоборот, с уменьшением числа Маха весомость влияния течения на функиию Грина уменьшается, проявляясь, кроме прочего, в уменьшении указанной ее асимметрии. В случае же отсутствия течения полученная функиия Грина является симметричной относительно этого сечения.

Ключевые слова: Функиия Грина, конвективное уравнение Гельмгольиа, прямая труба.

\section{A.O. Borysyuk}

Institute of Hydromechanics of the NAS of Ukraine, Kyiv

E-mail: aobor@ukr.net

\section{GREEN'S FUNCTION OF THE THREE-DIMENSIONAL CONVECTIVE HELMHOLTZ EQUATION FOR AN INFINITE STRAIGHT PIPE}

Green's function of the three-dimensional convective Helmholtz equation for an infinite straight pipe of arbitrary (but constant along its length) cross-sectional shape and area, having either acoustically rigid or acoustically soft walls or the walls of a mixed type, is constructed. This function is represented by a series in pipe acoustic modes. In the function, the effects of a uniform mean flow in the pipe are directly reflected. The effects become more significant, as the flow Mach number increases, and cause, in particular, the appearance and a further growth of the function asymmetry relative to the pipe cross-section, in which the acoustic source is located. Vice versa, the decrease of the Mach number results in the decrease of the effects and, in particular, the decrease of the indicated function asymmetry. In the absence of a flow, the obtained Green function is symmetric with respect to this cross-section.

Keywords: Green's function, convective Helmholtz equation, straight pipe. 